\title{
Clinical value of isotope encephalography
}

\author{
J. H. M. VAN ECK
}

\section{From the Departments of Neurology and Neurosurgery, and the Central Isotope Laboratory, University of Groningen, The Netherlands}

Since the work of Moore in the years 1948-53 the investigation of cerebral diseases by means of radioactive isotopes has developed in various directions, although it still has to find general acceptance. The technique used depends on the isotope chosen and on the way in which the gamma rays, emitted by the isotope, are counted and recorded.

In the U.S.A. manual scanning nowadays has been fully replaced by automatic procedures, consisting of either rectilinear or contour scanning, to which the possibility of section scanning has been added recently. The most current gamma emitters are ${ }^{131}$ I-tagged serum albumin (RISA) and ${ }^{203} \mathrm{Hg}$ labelled chlormerodrin; newer agents are ${ }^{197} \mathrm{Hg}$ and ${ }^{99 \mathrm{~m}} \mathrm{Tc}$. In some centres positron-emitters, such as ${ }^{74} \mathrm{As},{ }^{64} \mathrm{Cu}$, and ${ }^{18} \mathrm{~F}$, are used, which require more expensive equipment.

In Europe manual spot counting, under the name of gamma encephalography, has remained popular, thanks to the work of Planiol (Paris) and Mundinger (Freiburg), who are using RISA and ${ }^{206} \mathrm{Bi}$, respectively.

Advantages of the manual technique with a graphic analysis of the counting rates are: 1 The direct and perpendicular placing of the detector on the skull, which uniforms the volume of radioactive tissue 'seen'. The same is realized by contour scanning. 2 The possibility of recounting a suspect area without the necessity of repeating the whole test. 3 The systematic comparison between right and left, with unequivocal criteria for interpretation of the graphs. 4 The absence of any stress for the patient, who is allowed to move between counting two spots. An unexpected movement of the head cannot spoil the whole test.

Drawbacks of this method are: 1 It is laborious and time-consuming for the technicians who perform the measurements and have to calculate the differential rates and to diaw the graphs afterwards. 2 One does not have the disposal of separate lateral and anteroposterior views, which hampers a judgment on the depth of a lesion and even more so the detection of a midline lesion. 3 It can never show the shape and contours of a lesion as a scan does. 4 For outsiders the graphic presentation is less convincing than a scan, especially a photoscan.
The radiation dose to the patient is equal for both methods, depending only on the isotope and on certain protective measures. The span of time needed for obtaining diagnostic information has also more to do with the properties of the tracer than with the counting technique. In either instance one test takes little less than one hour. If knowledge about the nature of a lesion is wanted, testing on at least two successive days is necessary, whereas RISA and ${ }^{203} \mathrm{Hg}$-chlormerodrin require preparative treatment for protection of the thyroid gland and the kidneys, respectively. (This is not necessary when ${ }^{197} \mathrm{Hg}$ is used.)

It will be obvious that for the present isotope encephalography is unsuitable for real emergency, but further improvement in this respect may be brought by the use of other isotopes and further development of scintillation cameras (Gottschalk and Anger, 1965).

\section{DIAGNOSTIC POSSIBILITIES}

More than other investigators Planiol has stressed her ability to recognize the histological nature of a lesion (Table I). She states that in her material $90 \%$ of angiomas, $76 \%$ of meningiomas, $66 \%$ of glioblastomas and haematomas, and $62 \%$ of metastases answer the accepted criteria. From her data it can be calculated that a correct diagnosis of the nature of a lesion was possible in $58 \%$ of the total number of intracranial mass lesions.

TABLE I

SURVEY OF G.E.G. PICTURES IN VARIOUS DISORDERS (ACCORDING TO PLANIOL)

\begin{tabular}{lllll} 
Lesion & Intensity & Contours & $\begin{array}{l}\text { Time of } \\
\text { Appearance }\end{array}$ & $\begin{array}{l}\text { Evolution in First } \\
\text { 24 Hours }\end{array}$ \\
\hline Glioma $^{1}$ & High & Vague & Late & Progressive \\
Metastasis $^{2}$ & High & Sharp & Late & Very progressive \\
Meningioma & High & Sharp & Early & Slightly progressive \\
Angioma & High & Sharp & At once & Stationary \\
Abscess & High & Varied & Late & $\begin{array}{l}\text { Progressive } \\
\text { Haematoma }\end{array}$ \\
$\begin{array}{ll}\text { Moderate } \\
\text { Infarction }\end{array}$ & Moderate & Diffuse & Late & Progressive \\
& & & & $\begin{array}{l}\text { Eagressive or pro- } \\
\text { gressive }\end{array}$
\end{tabular}

${ }^{1}$ Unlike glioblastomas, astrocytomas not seldom are negative or when positive, of moderate intensity.

${ }^{2}$ In addition, metastatic foci may be small and multiple. 
Kalkman (1962a) added a so-called curve of disappearance, which requires measurements on at least four successive days. Its main practical advantage is that angiomas and meningiomas can be better distinguished: the former show a decreasing activity within the first 24 hours, the latter only between 24 and 48 hours, whereas in gliomas and metastases there is no decline before the third day.

Highest activity was also found by Schlesinger, deBoves, and Taveras (1962) soon after the injection of RISA in angiomas, but only at 24 hours in meningiomas; glioblastomas and metastases reached their peak at 48 hours; some astrocytomas (especially cystic ones) not before 72 hours after the injection.

Mundinger (1961) described 'syndromes' for various kinds of tumours too, but these cannot be easily compared with the aforesaid, as this author uses a different isotope $\left({ }^{206} \mathrm{Bi}\right)$, a special way of calculation, and a very personal terminology. A modification of his technique has been introduced by van der Werff, Prick, Walder, and Tan Wen Hian (1964).

Meanwhile it is remarkable that most investigators dwell upon the subject of localization, but little or not upon that of differentiation. This may have to do with the custom in many centres of performing a burr-hole biopsy in every case of intracranial spaceoccupying lesion.

\section{PATHOPHYSIOLOGY}

The explanation of the divergent behaviour of the various kinds of lesions lies in the circumstance that highly vascular lesions (angiomas, most meningiomas) already become radioactive when the best part of the injected isotope is still in the blood stream, whereas in other lesions the blood-brain-barrier has to be passed, which, even in cases of increased capillary permeability, takes some time.

Whether some isotopes play a role in the metabolism of tumours has not been proved with certainty. According to Mundinger and Gerhard (1963), who worked with incubation in vitro of animal tumour cells with tracer doses of radioisotopes, ${ }^{206} \mathrm{Bi}$, ${ }^{64} \mathrm{Cu}$, and ${ }^{203} \mathrm{Hg}$ enter the tumour cell, in contrast with RISA and ${ }^{74}$ As which accumulate in the extracellular space. On the other hand, Raimondi (1964), in an electron-microscopic study, could demonstrate RISA being picked up by human glioma cells. Tator, Morley, and Olszewski (1965) saw this in autoradiographs of brain tumour cells grown in tissue culture, but they were not sure if RISA was incorporated into the cells or absorbed on to their surface. Anyhow in contact autoradiographs of tumours in necropsy or surgical specimens the stroma was more radioactive than the parenchyma. It was also found that oedema- tous brain tissue, especially oedematous white matter, often was more radioactive than the adjacent tumour, which was ascribed to enlargement of the interstitial space.

\section{PRESENT MATERIAL AND RESULTS}

Between September 1962 and July 1965 a series of 335 patients was examined by Planiol's method of manual gamma encephalography. For each gamma encephalogram (G.E.G.) cranial radioactivity was measured on 24 symmetrical positions on each half of the scalp and on six median positions, one to two hours and 24 hours (sometimes also 48 hours) after intravenous injection of 6-7 microcuries of RISA per kilogram body weight. In every patient the thyroid gland had been blocked by inactive iodine beforehand. Only recently we started using ${ }^{203} \mathrm{Hg}$ chlormerodrin, which, by its faster uptake and clearance from the blood, is more suitable for ambulatory practice.

Out of these 335 patients, 143 turned out to be suffering from focal intracranial disease, among whom 116 harboured an expanding lesion. Table IL shows our results with this latter category. Ous

\section{TABLE II}

RESULTS OF GAMMA ENCEPHALOGRAPHY IN 116 SPACE OCCUPYING LESIONS

\begin{tabular}{lrrr} 
Type of Lesion & Total & Positive & Negat \\
\hline Gliomas & 33 & 27 & 6 \\
Brain metastases & 31 & 28 & 3 \\
Skull metastases & 4 & 1 & 3 \\
Meningiomas & 10 & 9 & 1 \\
Angiomas and vascular malformations & 9 & 5 & 4 \\
Acoustic neuromas & 5 & 2 & 3 \\
Pituitary adenomas and pinealomas & 3 & 0 & 3 \\
Unspecified tumours & 5 & 2 & 3 \\
Abscesses and empyemas & 7 & 7 & 0 \\
Haematomas & 9 & 5 & 4 \\
Total number of lesions & 116 & 86 & 30
\end{tabular}

criterion for a positive G.E.G. was a reproducible differential counting rate of at least $20 \%$ between two or more symmetrical positions. Thus $74 \%$ of all lesions could be detected and correctly localized. Among the 30 negative cases 16 had midline or posterior fossa lesions; among the 86 positive cases only seven had such lesions. This means that for supratentorial hemisphere lesions the G.E.G. was positive in $85 \%$ of cases.

Planiol (1963) reports an overall accuracy of $83 \%$ versus $89 \%$ for supratentorial hemisphere lesions. Figures given by representatives of several schools of automatic scanning, during the last five years, vary between $70 \%$ and $90 \%$, both for RISA and for mercurial compounds. Such figures, however, depend so much on the composition of the series that 
their value is far from absolute. For as soon as the possibilities of a new diagnostic test become known, selection of patients can hardly be avoided on the part of the referring clinicians: in patients with tumours of the sellar region, brain-stem or posterior fossa, for instance, isotope studies will but seldom be asked for. In our material no less than $20 \%$ of cases belong to these categories, against $15 \%$ in Planiol's material. It is not surprising that Wende (1963a), by refraining from the investigation of infratentorial lesions, obtained positive results in $92 \%$ of his cases. Furthermore, the results may be influenced by knowledge of the clinical history.

As to the nature of the lesions, this could be correctly indicated in about one half of the 86 positive cases, which tempered our optimism in this respect.

GLIOMAS AND MENINGIOMAS Most important to the clinician is the differentiation between these two kinds of tumours, which should be easy with the criteria given in Table I: late uptake and vague contours for gliomas (Fig. 1), early uptake and sharp borders for meningiomas (Fig. 2). However, a clear definition of the terms 'sharp' and 'vague' has never been given. Furthermore, in Planiol's own material no less than $31 \%$ of the gliomas had an early uptake and $17 \%$ of the meningiomas had a late uptake. In a more recent publication (Planiol, Metzger, and David, 1964) she described the case of a meningioma, which acquired the early uptake type only in the course of its development.

Most of the 27 gliomas detected by the isotope test had a late uptake, but their contours often were rather sharp. We never saw a slight and diffuse hyperactivity of the whole ipsilateral hemisphere, as Planiol did. Three of the six cases of glioma missed by us could not befollowed up for more than 24 hours, which might have enlarged the chance of success.

The only case of meningioma we could not trace had a parasellar location. In three of the remaining nine cases there was no distinct hyperactivity before 24 hours after the injection (as indicated by Schlesinger et al., 1962), which made us mistake them for gliomas. One of them was calcified, two others were deep-seated falx meningiomas. On the other hand, not only a superficial and vascular glioma but also a metastatic lesion of the skull vault simulated a meningioma by its early uptake. We feel that this early hyperactivity has not only to do with the vascularity of a tumour, but also with its superficial situation.

METASTATIC CARCINOMA Two of the three negative brain metastases were situated in the cerebellum. All 28 positive ones fulfilled the condition of late hyperactivity and rather sharp contours (Fig. 3). Unlike

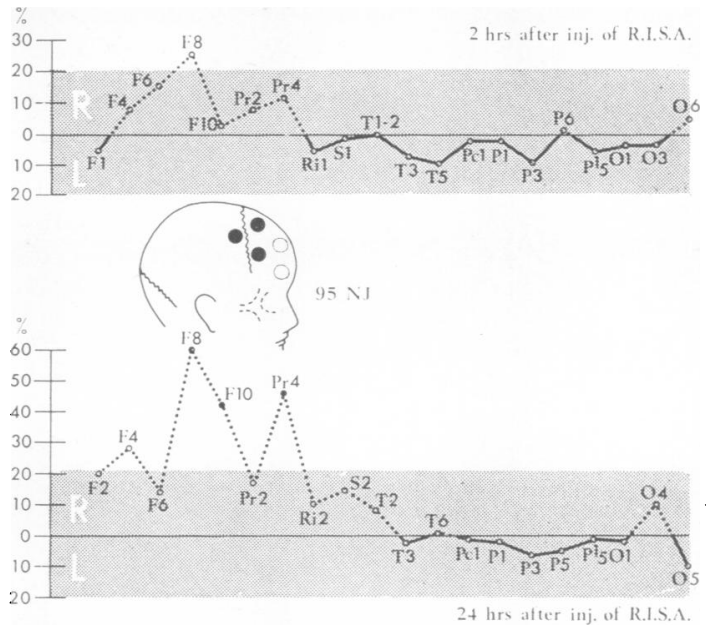

FIG. 1. Gamma encephalogran of a patient with a right frontal glioma. The graphs indicate the differential uptake between right and left hemisphere (even numbers right, uneven numbers left). $F=$ frontal, $P r=$ precentral, $T=$ temporal, $P=$ parietal, $O=$ occipital, $C=$ cerebellar. The Sylvian fossa is marked by $R i, S$ and $P c$.

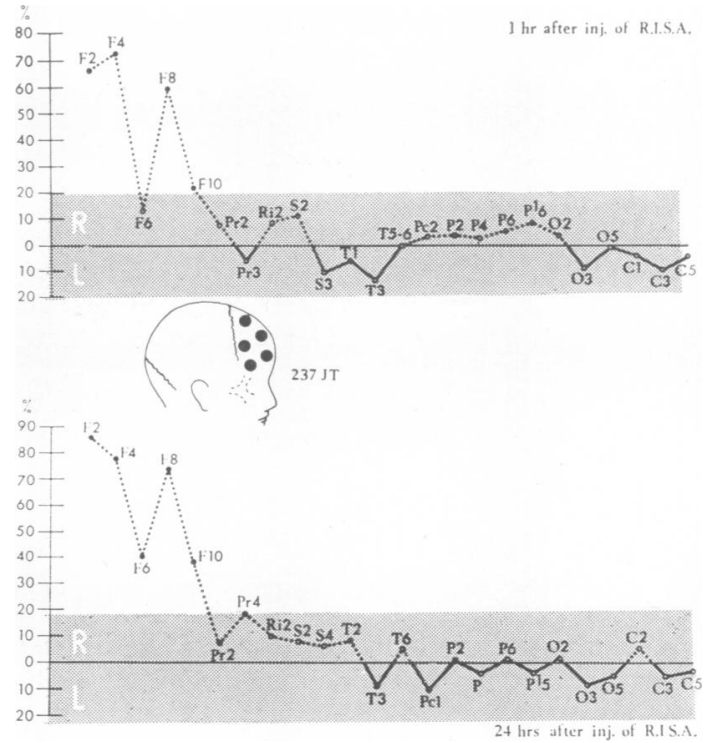

FIG. 2. Gamma encephalogram of a patient with a right frontal meningioma. 


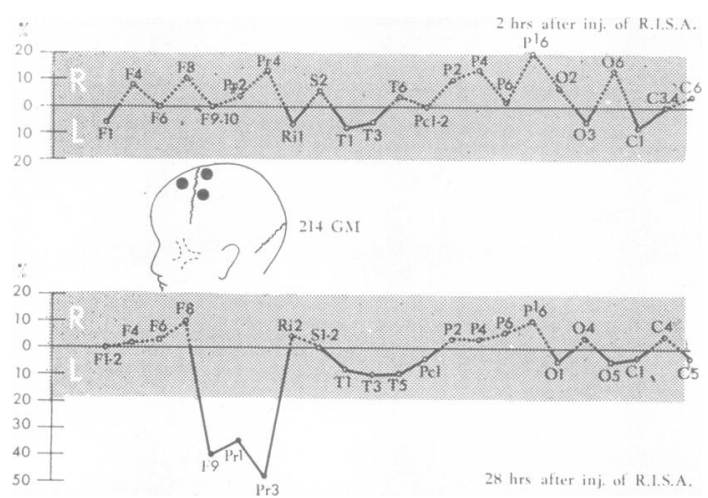

FIG. 3. Gamma encephalogram of a patient with a left frontocentral metastosis of a bronchial carcinoma.

the gliomas, most of them did not even show a slight anomaly after one hour, which is reflected in the average value for the first day (Table III).

\section{TABLE III}

AVERAGE VALUES OF HYPERACTIVITY IN FOUR TYPES OF LESION

\begin{tabular}{lccc} 
Type of Lesion & First Day & Second Day & Ratio \\
\hline Meningiomas & 40 & 53 & 0.75 \\
Gliomas & 26 & 51 & $0 \cdot 51$ \\
Metastases & 14 & 48 & $0 \cdot 29$ \\
Abscesses & 19 & 51 & 0.37
\end{tabular}

A problem in this category is formed by multiplicity: in nine of 10 necropsy cases multiple intracerebral deposits were found, which had been predicted by the G.E.G. in only one. It is true that most of these nodules were small, and that there often was an interval of some weeks between the isotope study and death. But one should by no means rely on surgical findings alone to conclude that a metastatic lesion is a solitary one. The G.E.G. indicated multiplicity in some further cases, where no necropsy control was possible, and in a case of multilocular gliomas, confirmed at necropsy.

As to the skull metastases, the one positive was in the vault and the three negatives were in the base of the skull.

ANGIOMAS AND VASCULAR MALFORMATIONS These highly vascular lesions in our series did not behave uniformly. One large and superficial racemose angioma was markedly hyperactive immediately after the injection as well as on the next two days (Fig. 4). Another two of the same variety, but of a deeper situation, showed an unmistakable regressive hyperactivity, i.e., that it had almost disappeared after 24 hours.
In two cerebellar hemangioblastomas the hyperactivity was moderate and stationary; in a third one $\underset{\mathbb{Q}}{Z}$ it was masked by anatomical changes due to a previous operation. A carotico-cavernous fistula and two smaller arteriovenous shunts could not be detected. Saccular aneurysms were not studied.

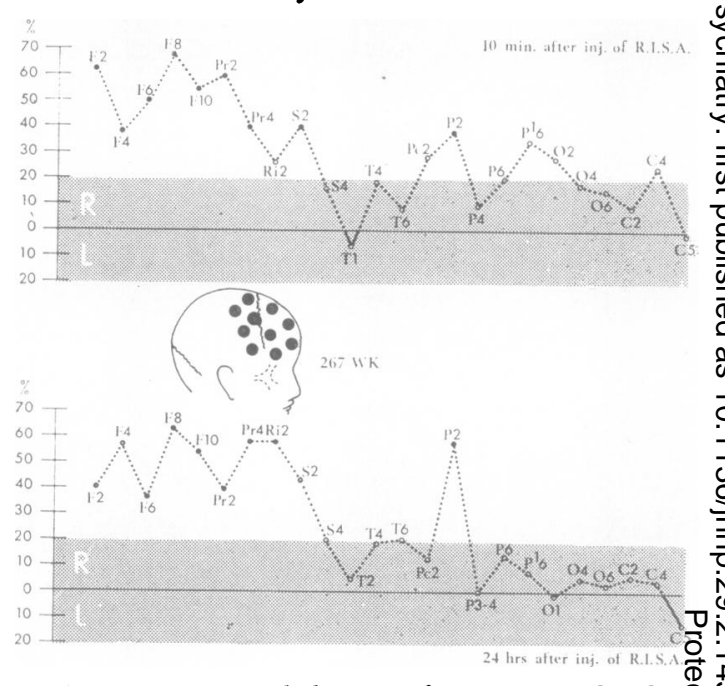

FIG. 4. Gamma encephalogram of a patient with a larg o arteriovenous angioma in the anterior half of the righe hemisphere.

HAEMATOMAS At first our results in intracerebra blood clots were disappointing, in contrast Planiol's but in accordance with Mouchette's (1963) findings. Apparently we should have continued our measurements, as recommended by Fieschi, Mastropaolo, and Agnoli (1961); in two recent cases we were more successful. Two chronic subdural haematomas were clearly positive on the second day, with a rather $\$$ diffuse spreading (Fig. 5); one extradural haema- $\overrightarrow{\overrightarrow{0}}$ toma gave only discrete anomalies and in a smaller area than could have been expected.

In four instances we were able to compare the radioactivity of the surgically removed clot with that of the circulating blood. In the extradural haematoma of a fortnight's standing this ratio was $1: 5 ;-$ in a subdural haematoma several months' old it was 3 . $1: 7$, the capsule being three times more active than 8 the clot itself. In two intracerebral haematomas 3 two to three weeks' old it was $1: 5$ and $1: 9$, respec- 9 tively.

Similar observations have been reported by Gros, $\frac{D}{2}$ Gonsette, and Vlahovitch (1960), Fieschi et al. (1961), Sweet, Mealey, Aronow, and Brownell (1961), 요 Feindel, Rovit, and Stephens-Newsham (1961), and N Mouchette (1963). As the activity of the normal N brain in the first 24 hours after intravenous adminis- $\frac{\omega}{\sigma}$ 

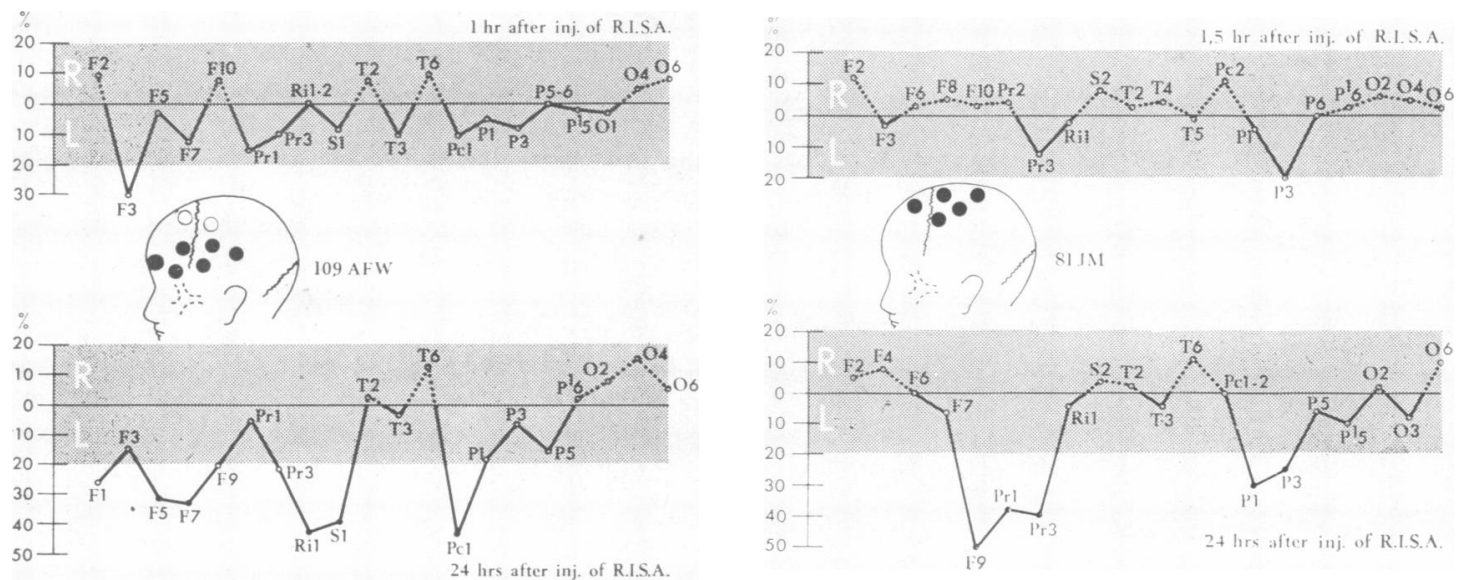

FIG. 5.

FIG. 6.

FIG. 5. Gamma encephalogram of a patient with a subdural haematoma over the anterior part of the left hemisphere.

FIG. 6. Gamma encephalogram of a patient with a left frontoparietal brain abscess.

tration of RISA appears to approximate $15 \%$ of that of the circulating blood, it is unlikely that the haematoma itself is responsible for the hyperactivity in cases where this occurs. In subdural haematomas the capsule seems to be liable for the uptake; in intracerebral haematomas the mechanism is not quite clear (oedema of the surrounding brain tissue may play a part).

ABSCESSES AND EMPYEMAS In these inflammatory lesions the isotope likewise accumulates in the capsule more than in the pus, as has been demonstrated by Gros et al. (1960) by means of autoradiography, and by Sweet et al. (1961) by direct measuring of surgical specimens. In one of our own patients with a subdural empyema the activity ratio pus/blood was $2: 3$, whereas the activity of the capsule was twice that of the adjacent brain tissue.

Not a single abscess in our series failed to reveal itself by a positive G.E.G., which confirms the excellent results reported by Sweet et al. (1961), Planiol (1963), Wilcke (1964), and many others. The picture was that of a late hyperactive area with rather sharp boundaries (Fig. 6). Without knowledge of the clinical background it would not have been possible to distinguish them from neoplastic lesions.

OCCLUSIVE VASCULAR DISEASE In Planiol's material (1963) brain infarctions gave abnormalities in the G.E.G. in only 10 to $15 \%$ of cases. These abnormalities consisted of either progressive (tumour type) or regressive hyperactivity (see Table I). In our opinion, the regressive type is not specific for encephalomalacic lesions, as we saw it in deep vascular malformations as well.
We have the impression that the incidence of abnormalities is much higher than $15 \%$, when the test is done within two weeks after the cerebrovascular accident, although a longer interval does not exclude them (Fieschi et al., 1961; Ojemann, Aronow, and Sweet, 1964; Overton, Haynie, and Snodgrass, 1965; Morrison, Afifi, Van Allen, and Evans, 1965; Waxman, Ziegler, and Rubin, 1965). In our series hyperactivity always was of the tumour type but, unlike in real tumours, was not found again when the test was repeated after a few weeks (Figs. 7 and 8). Secondly, the anomalies correlate in some measure with the neurological deficit; they do not occur in so-called transient ischaemic attacks. Infarctions of longer standing may lead to brain atrophy and this loss of tissue may manifest itself by hyporadioactivity in the G.E.G. (Gros et al., 1960; Fieschi et al., 1961).

CYSTIC LESIONS Most authors found that cystic tumours were difficult to detect, which implies a low uptake of the isotope. Some authors (Gros et al., 1960; Magalotti and Hummon, 1960) even saw hyporadioactivity in a tumour area, which could result in an erroneous lateralization if hyperactivity was supposed to be present on the normal side. This was contradicted by Di Chiro (1961), who made good localizing scans in tumoral cysts; he believes that only poro-encephalic cysts have a low uptake.

According to Gros et al. (1960) and Tator et al. (1965), two kinds of cysts exist: those in which the cystic content is a clear fluid, containing little albumin, which does not coagulate spontaneously and takes up little RISA. The other variety contains a yellow or dark fluid, rich in albumin, which solidifies 


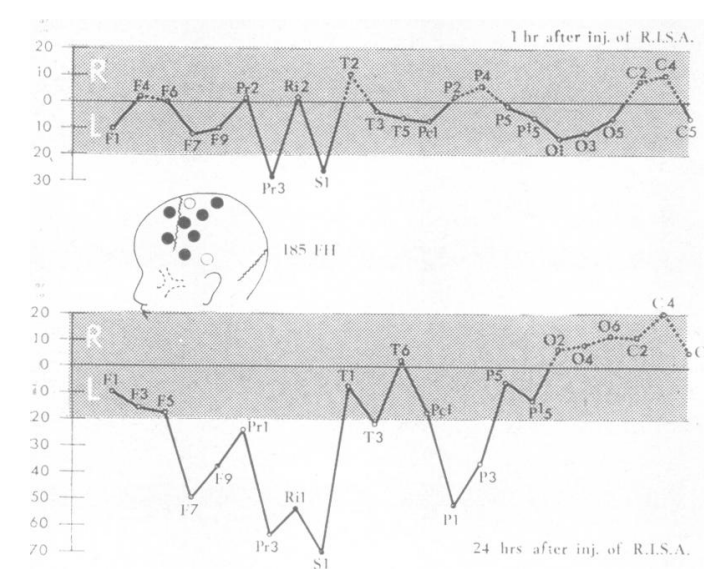

FIG. 7. Gamma encephalogram of a patient with an occlusion of the left middle cerebral artery, one week after the accident.

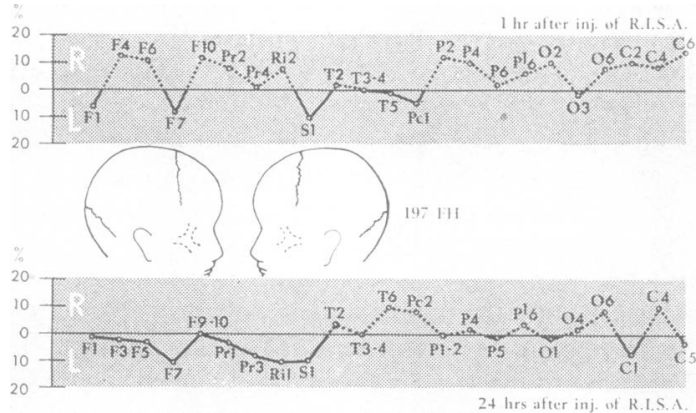

FIG. 8. Gamma encephalogram of the same patient, four weeks after the accident. The anomalies have completely disappeared.

on standing and takes up an appreciable amount of RISA.

Our own experience with cysts is limited. Only one of the five gliomas missed by us was a cystic one. A sample of cystic fluid from a metastatic carcinoma, inaccurately localized by the isotope test, was five times less active than the circulating blood. To date we have never seen a neoplastic lesion causing hyporadioactivity in the gamma electroencephalogram.

MISCELLANEOUS CONDITIONS We could confirm that localized cerebral atrophy, for instance posttraumatic or post-operative, may cause hyporadioactivity (Vlahovitch and Temple, 1960).
Benign osteomas of the skull are not hyperactive. In a patient with Paget's disease of the skull, however, the local areas of hyperostosis were markedly hyperactive after 24 hours, a similar observation as has been reported by Sweet et al. (1961) and by McAfee and Taxdal (1961).

In a case of haemorrhagic encephalitis of the left temporal lobe we found typical signs of local hyperaemia, viz., stationary hyperactivity on the first and second day. Wilcke (1962) also mentions such a case.

In several other organic cerebral disorders, as for instance disseminated sclerosis, neurosyphilis, and general paralysis, no abnormalities were seen in the G.E.G.

RADIOMERCURY Blau and Bender (1962) found that neohydrin (chlormerodrin) labelled with mercury-203 could localize some lesions that RISA could not. This did not occur in patients submitted to double isotopic studies by Feindel, Yamamoto, and Rumin (1964a), by Mealey, Dehner, and Reese (1964), and by ourselves. Yet we were able to confirm that the differential uptake in some tumours was twice as high as with RISA. Radiomercury, at least ${ }^{203} \mathrm{Hg}$, can be used for manual scanning, but it is more suitable for automatic procedures. ${ }^{197} \mathrm{Hg}$, introduced by Sodee (1963), proved to be as effective as ${ }^{203} \mathrm{Hg}$ (Yamamoto, Feindel, and Zanelli, 1964; Rhoton, Carlsson, and Ter-Pogossian, 1964; Bucy and Ciric, 1965; Overton, Otte, Beentjes, and Haynie, 1965), and it is much safer for the kidneys, being short-lived and without beta emission.

\section{INDICATIONS FOR ISOTOPE ENCEPHALOGRAPHY}

LATE EPILEPSY In epilepsy of late onset this method may be useful as a screening test for out-patients, in addition to the E.E.G. and echogram. If we only consider those patients who have generalized seizures without neurological signs during the intervals, the number of tumours detected in this way is small. On the other hand, a negative G.E.G., especially when associated with a normal E.E.G. and echogram, can be a reassurance for doctor and patient. So there will be a number of patients who need not be admitted to hospital for air studies.

CANCER PATIENTS Patients with a carcinoma are often referred for a neurological examination, in order to exclude brain metastases before deciding to venture an attack on the primary tumour. Just as in the epileptic group, isotope studies are complementary to clinical impression and E.E.G., but the absence of brain involvement can never be guaranteed. 
In those patients where cerebral symptoms develop after the primary tumour has been operated upon, knowledge about the existence of multiplicity is wanted for evaluation of neurosurgical possibilities. Unfortunately, necropsy not seldom reveals multiple nodules, which escaped every diagnostic test (van Eck, Go, and Ebels, 1965).

DIAGNOSTIC PROBLEMS In some patients clinical symptoms suggest a mass lesion within the skull, but neuroradiological findings are dubious or negative. Isotope encephalography may be of help in such cases. In 12 cases from the present series the G.E.G. was more conclusive than the angiogram, in two cases even more conclusive than any other diagnostic procedure. At present, with some exceptions (Sweet et al., 1961; Di Chiro, 1961; Brinkman, Wegst, and Kahn, 1962; Wilcke, 1962), most neurosurgeons are still reluctant to operate on the basis of a brain scan alone, although falsepositives seldom occur.

From Table I it will be clear that the isotope test can also fail when other procedures lead to the right diagnosis. A more detailed comparison of the results of E.E.G., isotope studies, and neuroradiology will be published elsewhere.

ADDITIONAL INFORMATION In some instances of an already known brain tumour the neurosurgeon wants additional information on the exact site and on the nature of the growth. In nearly all patients with a positive G.E.G. we were able to indicate the right place for a craniotomy; only once we were misled, as we think, by cerebral oedema. To ascertain the depth of a lesion by our technique is much more difficult than by automatic scanning, which provides us with a lateral and a frontal view.

As to the size of the lesion, the area of hyperactivity marked on the patient's scalp is usually larger than its real dimension, although this partly depends on the type of collimator used. We already mentioned that the nature of a lesion cannot always be predicted with accuracy.

RECURRENT TUMOURS In suspected recurrence of a brain tumour E.E.G. and neuroradiology may be less reliable as a result of the anatomical changes due to the previous operation (Ashkenazy, 1953). For the isotope test this is not an obstacle, except during the first three months after surgery, when a local breakdown of the blood-brain barrier may still be present.

Planiol and Pertuiset (1962) report a very high percentage of positive findings, $93 \%$, owing to the positive selection in such material: deep-seated lesions are often inaccessible to neurosurgical inter- vention and therefore are excluded from postoperative control groups. Moreover, as has been suggested by Kvičala and Bouček (1962), in most recurrent tumours there will be less normal brain tissue overlying the lesion than in tumours which have not yet been operated upon.

We examined 20 such patients: 10 of them had a recurrent tumour, which gave a positive G.E.G. in nine. Only one cystic oligodendroglioma was negative. In the remaining 10 patients removal of the tumour, mostly a meningioma, seemed to have been complete. We also saw areas of hyperactivity disappear after $x$-ray treatment, as has been described by Wende (1963b).

\section{DISCUSSION}

Our own results concur with those of other authors and confirm the clinical value of the method described above. As its diagnostic reach proves to be different from that of electro-encephalography and neuroradiology, it should be regarded as complementary to these procedures.

It remains to be seen if, when isotope encephalography reveals an unmistakable expanding lesion, we can dispense with neuroradiological examination, as is done in a few centres, especially when an abscess is concerned. But there is no doubt that the method has already reduced the need for more traumatic procedures in elderly people and in cancer patients. In epilepsy of late onset it is a useful ambulatory screening test for out-patients, which entails minimal hazard and discomfort to the patient. The radiation dose is admissible and can be further lowered by the use of ${ }^{197} \mathrm{Hg}$.

It is to be expected that in the near future isotope encephalography will also become suitable for emergency cases, when scintillation cameras can be used with such short-lived compounds as technetium99m (Medical Radioisotope Scanning, 1964; Witcofski, Maynard, and Meschan, 1965; Gottschalk and Anger, 1965; Bucy and Ciric, 1965). The respective merits of the manual and the automatic technique have been discussed earlier in this paper. We feel that, in skilled hands, their overall accuracy will never be very dissimilar. Representatives of both 'schools' met on more than one occasion, for instance in Strasbourg (Planiol, 1965), but a comparative study was never published.

At all events, whatever method one prefers and in spite of technical progress, a certain percentage of failures will remain, as long as some lesions do not have a higher uptake than their surroundings. In our opinion, however, the potentiality of recognizing the nature of lesions deserves more attention and may be further improved. 


\section{SUMMARY}

After a discussion of various techniques of isotope encephalography the results of this method in a series of 335 patients are reported. Planiol's method of manual spot counting was used, after intravenous injection of radioactive iodinated human serum albumin.

In 86 of 116 patients with an intracranial spaceoccupying lesion this lesion could be correctly localized. In some instances the isotope studies were more informative than neuroradiological contrast studies. Softenings of the brain may also be localized, provided that they are examined in an early stage. The nature of a brain lesion can sometimes be recognized, when the isotope test is performed on at least two successive days.

The field of clinical application for this diagnostic procedure is outlined. Isotope encephalography is to be considered as a useful tool in the neurologist's and the neurosurgeon's arsenal.

My thanks are due to Dr. M. G. Woldring, Head of the Central Isotope Laboratory, for his hospitality, and to Miss A. K. van Zanten for her technical assistance.

\section{BIBLIOGRAPHY}

Ashkenazy, M. (1953). The detection of intracranial lesions, especially recurrent tumors, by the use of radioactive isotopes and the scintillation counter. J. Amer. pharm. Ass. (sci. Ed.), 42, 125-126.

Blau, M., and Bender, M. A. (1962). Radiomercury labeled neohydrin: a new agent for brain tumor localization. $J$. nucl. Med., 3, 83-93.

Brinkman, C. A., Wegst, A. V., and Kahn, E. A. (1962). Brain scanning with mercury ${ }^{203}$ labeled neohydrin J. Neurosurg., 19, 644-649.

Bucy, P. C., and Ciric, I. S. (1965). Brain scans in diagnosis of brain tumors. J. Amer. med. Ass., 191, 437-443.

Bull, J. W. D., and Marryat, J. (1965). Isotope encephalography: experience with 100 cases. Brit. med. J., 1, 474-480.

Di Chiro, G. (1961). RISA encephalography and conventional neuroradiologic methods. Acta Radiol. (Stockh.), suppl. no. 201

Dugger, G. S., and Pepper, F. D. (1963). The reliability of radioisotopic encephalography. Neurology (Minneap.), 13, 1042-1053.

Eck, J. H. M. van, Weenink, H. R., and Woldring, M. G. (1964). Ervaringen met gamma-encefalografie. Ned. T. Geneesk, 108, 2117-2122.

_- Go, K. G., and Ebels, E. J. (1965). Metastatic tumours of the brain. Psychiat. Neurol. Neurochir. (Amst), in the press.

Feindel, W., Rovit, R. L., and Stephens-Newsham, L. (1961). Localization of intracranial vascular lesions by radioactive isotopes and an automatic contour brain scanner. J. Neurosurg., 18, 811-821.

_- Yamamoto, Y. L., and Rumin, N. (1964a). Comparison of radioactive iodinated serum albumin and radioactive mercury $y^{203}$ for brain scanning. Ibid., 21, 1-6.

—, Yamamoto, Y. L., McRae, D. L., and Zanelli, J. (1964b). Contour brain scanning with iodine and mercury compounds for detection of intracranial tumors. Amer. J. Roentgenol., 92, 177-186.

Fieschi, C., Mastropaolo, C., and Agnoli, A. (1961). L'impiego della sieroalbumina radioiodata nella diagnosi delle lesioni cerebrali. Sist. nerv., 13, 435-454.

Gottschalk, A., and Anger, H. O. (1965). Use of the scintillation camera to reduce radioisotope scanning time. J. Amer. med. Ass., 192, 448-452.
Gros, C., Gonsette, R., and Vlahovitch, B. (1960). L'usage des isotopes en neuro-chirurgie. Montpellier méd., 47, 192-211.

Kalkman, H. J. (1962a). Over gamma-encefalografie. Thesis, Amsterdam University.

- (1962b). Gamma-encephalographie, diagnostiek van hersenziekten met radioactieve isotopen. J. belge. Radiol., 45, 307-314.

Kvicala, V., and Bourek, J. (1962). Die Bedeutung der Gammaenzephalographie für die Diagnostik von Hirngeschwulstrezidiven. $Z$ bl. Neurochir., 23, 12-22.

Magalotti, M. F., and Hummon, I. F. (1960). Localization of intracranial lesions by radioactive isotopes. Amer. J. Roentgenol., 83, 135-144.

McAfee, J. G., and Taxdal, D. R. (1961). Comparison of radioisotope scanning with cerebral angiography and air studies in brain tumor localization. Radiology, 77, 207-222.

Mealey, J., Dehner, J. R., and Reese, I. C. (1964). Clinical comparison of two agents used in brain scanning: RISA vs Chlormerodrin $\mathrm{Hg}$ 203. J. Amer. med. Ass., 189, 260-264.

Medical Radioisotope Scanning (1964). Proceedings of the symposium held in Athens, 20-24 April 1964. International Atomic Energy Agency, Vienna.

Moore, G. E. (1953). Diagnosis and localization of brain tumors. Thomas, Springfield, Illinois.

Morrison, R. T., Afifi, A. K., Van Allen, M. W., and Evans, T. C. (1965). Scintiencephalography for the detection and localization of non-neoplastic intracranial lesions. J. nucl. Med., 6, 7-15.

Mouchette, R. (1963). La gamma-encéphalographie. Rev. méd. Liège, 18, 278-284.

Mundinger, F. (1961). The localisation of brain tumours by means of radio-isotopes. Medicamundi, 7, 61-66, 81-91, and 127-130.

- , and Gerhard, H. (1963). Untersuchungen über die Verteilung der zur Hirntumordiagnostik verwendeten Radioisotope in der Blutbahn, in experimentellen Tumoren und menschlichen Hirngegeschwülsten. Acta neurochir. (Wien), 11, 398-415.

Ojemann, R. G., Aronow, S. A., and Sweet, W. H. (1964). Scanningówith positron-emitting radioisotopes: Occlusive cerebrafo vascular disease. Arch. Neurol. (Chic.), 10, 218-228.

Overton, M. C., Haynie, T. P., and Snodgrass, S. R. (1965). Brain(D) scans in nonneoplastic intracranial lesions. J. Amer. med. Ass., 191, 431-436.

- Snodgrass, S. R., and Haynie, T. P. (1965). Brain scans in neoplastic intracranial lesions. Ibid., 192, 747-751.

-, Otte, W. K., Beentjes, L. B., and Haynie, T. P. (1965). A com? parison of ${ }^{187}$ mercury and ${ }^{203}$ mercury chlormerodrin in clinical brain scanning. J. nucl. Med., 6, 28-38.

Planiol, T. (1963). La gamma-encéphalographie. Rev. Prat. (Paris) $13,3625-3652$.

- editor (1965). Radio-isotopes et affections du système nerveux central. Masson, Paris.

-, and Pertuiset, B. (1962). Diagnostic des récidives de tumeurs intracraniennes par la gamma-encéphalographie (Etude de 200 cas). Neuro-chirurgie, 8, 14-21.

- Metzger, J., and David, M. (1964). Intérêt de l'association gamma-encéphalographie-angiographie carotidienne pour le diagnostic de nature des néoformations intracraniennes sustentorielles. Ibid., 10, 23-36.

Raimondi, A. J. (1964). Localization of RISA in human glioma. Arch. Neurol. (Chic.), 11, 173-184.

Rhoton, A. L., Carlsson, A. M., and Ter-Pogossian, M. M. (1964) Brain scanning with chlormerodrin $\mathbf{H g}^{197}$ and chlormerodrin $\mathrm{Hg}^{203}$. Ibid., 10, 369-375.

Schlesinger, E. B., deBoves, S., and Taveras, J. (1962). Localizatio of brain tumors using RISA. Amer. J. Roentgenol., 87, 449-462,

Sodee, D. B. (1963). A new scanning isotope, ${ }^{197}$ mercury. J. nucl. Med. 4, 335-344.

Sweet, W. H., Mealey, J., Aronow, S., and Bronwell, G. L. (1961) Localization of focal intracranial lesions by scanning of rays from position-emitting isotopes. Clin. Neurosurg., 7, 159-199.

Tator, C. H., Morley, T. P., and Olszewski, J. (1965). A study of the factors responsible for the accumulation of RIHSA by intracranial tumors and other lesions. J. Neurosurg., 22, 60-76.

Vlahovitch, B., and Temple, M. (1960). La gamma encéphalographie dans les atrophies cérébrales. Montpellier méd., 57, 212-217.

Waxman, H. J., Ziegler, D. K., and Rubin, S. (1965). Brain scans in diagnosis of cerebrovascular disease. J. Amer. med. Ass., 192, 453-456.

Wende, S. (1963a). Technik und Wert der Gamma-Enzephalographie. Fortschr. Röntgenstr., 98, 466-476. 
Wende, S. (1963b). Das radiologisch ausgelöste Hirnödem und seine Verhütung. Ibid., 98, 589-598.

Werff, J. Th. van der, Prick, J. J., Walder, H. A. D., and Tan Wen Hian. (1964). Gamma-encefalografie. Ned. T. Geneesk., 108, 646-651.

Wilcke, O. (1962). Hirntumor-Diagnostik mit Positronenstrahlern. Acta neurochir. (Wien.), 10, 301-319.
(1964). Möglichkeiten und Grenzen der Hirntumordiagnostik mit Positronenstrahlern. Neurochirurgia (Stuttg.), 7, 33-41.

Witcofski, R., Maynard, D., and Meschan, I. (1965). The utilization of $99 \mathrm{~m}$ technetium in brain scanning. $J$ nucl. Med , 6, 121-130.

Yamamoto, Y. L., Feindel, W., and Zanelli, J. (1964). Comparative study of radioactive chlormerodrin (Neohydrin) tagged with ${ }^{197}$ mercury and ${ }^{203}$ mercury for brain scanning. Neurology (Minneap.), 14, 815-820. 